\title{
Entre los principios y los fines. Ética y estética en el episodio EI Tirano de la serie House
}

\section{Ignacio GAZTAKA EGUSKIZA}

Universidad del País Vasco (UPV/EHU) (España).

Autor para correspondencia: Ignacio Gaztaka Eguskiza. Correo electrónico: igastaca001@ikasle.ehu.eus, gatazka93@gmail.com

Recibido el 26 de octubre de 2019; aceptado el 28 de noviembre de 2019.

Cómo citar este artículo: Gaztaka Eguskiza I. Entre los principios y los fines. Ética y estética en el episodio "El Tirano" de la serie House. Rev Med Cine [Internet] 2020;16(x): $\mathrm{xx}-\mathrm{xx}$

DOI:

\section{Resumen}

Este artículo profundiza en los acontecimientos narrados en el cuarto episodio de la sexta temporada de la serie House M.D. (título en inglés, en España es conocida como House o Dr. House). En él, el Doctor Chase se ve en el dilema de tratar a un dictador africano. Por un lado, el juramento hipocrático al que está ligado le obliga a sanar a su paciente, sin embargo, su moral individual lo empuja a tomar una decisión fatal. Y es que en eso estriba la peculiaridad ética de esta narración, en el choque de actitudes que codifican lo que se considera "el deber". Entre los principios y los fines, es el territorio en el que Chase se encuentra perdido. Una tierra de nadie que atormenta al profesional de la medicina, en general, y al Doctor Chase, en particular. El análisis cinematográfico dilucidará las claves éticas (temas) y estéticas (estrategias narrativas) de esta obra. El demiurgo que controla los aconteceres de la narración decide que el doctor tome el bando de los fines, aunque eso no signifique que sea lo correcto. Sin pretender ser ejemplo de lo que debiera hacerse en la vida real, esta obra, junto al estudio de la misma, invitan a explorar los límites de la deontología médica.

Palabras clave: House; cine; ética; deontología; utilitarismo.

\section{Between principles and purposes. Ethics and aesthetics in the episode The Tyrant of the House M. D. Series}

\section{Summary}

This article delves into the events narrated in the fourth episode of the sixth season of House M.D. In it, Dr. Chase finds himself in the dilemma of treating an African dictator. On the one hand, the Hippocratic oath to which he is bound forces him to heal his patient, however, his individual morale pushes him to make a fatal decision. And it is that, in that lies the ethical peculiarity of this narrative, in the clash of attitudes that codify what is considered "duty". Between principles and ends, it's the territory in which Chase is lost. A no man's land that torments the medical professional, in general, and Dr. Chase in particular. Cinematic analysis will elucidate the ethical (themes) and aesthetic keys (narrative strategies) of this work. The demiurge that controls the storytelling happenings decides that the doctor takes the side of the ends, even if that does not mean that it is the right thing to do. Without pretending to be an example of what should be done in real life, this article, with the study of it, invites to explore the limits of medical deontology.

Keywords: House; cinema; ethics; deontology; utilitarianism. 


\section{Ficha técnica}

Título de la serie: House M. D. (2004-2012). Título del episodio: El tirano (España). The tyrant (Estados Unidos). Episodio 3 / Temporada 6.

País: Estados Unidos.

Año: 2009 (5 de octubre).

Dirección: David Straiton.

Guión: David Shore y Peter Blake.

Intérpretes: Hugh Laurie, Lisa Edelstein, Omar Epps, Robert Sean Leonard, Jennifer Morrison, Jesse Spencer, Olivia Wilde, James Earl Stones.

Color: color.

Duración: 43 minutos.

Género: drama; misterio; thriller; médico.

Sinopsis: cuando un polémico político africano se enferma, es llevado a Princeton Plainsboro para recibir tratamiento. El equipo de House discute sobre si es conveniente ayudar a un dictador despiadado que ha sido citado por crímenes contra la humanidad en su país. Mientras tanto, Wilson intenta hacer las paces con un vecino veterano de Vietman, pero la falta de disciplina de House exacerba el problema.

\section{Enlaces:}

https://www.imdb.com/title/tt1503408

\section{Introducción}

House M. D. es una serie de televisión estadounidense creada por David Shore y producida por la cadena FOX. Tuvo una longevidad de ocho temporadas (20042012) en los que la serie cosechó grandes éxitos, tanto de crítica como del público. Ha recibido numerosos reconocimientos y nominaciones, entre los que destacan dos Globos de Oro (2006 y 2007) y dos premios Emmy (2005 y 2008).

"Es considerada como una de las series más vistas en todo el mundo: 66 países llegaron a emitirla simultáneamente. Con una media de 15 millones de espectadores en el primer pase de cada episodio en EEUU, llegó a reunir a más del doble en su minuto de oro, en el episodio 12 de su tercera temporada. Su capítulo final, titulado Everybody dies (Todo el mundo muere), retransmitido el 21 de mayo de 2012, reunió a más de 10 millones de personas en una emisión que aunó éxito de crítica y público"1.

En este caso, se centra la atención sobre un capítulo en especial. El cuarto episodio de la sexta temporada,

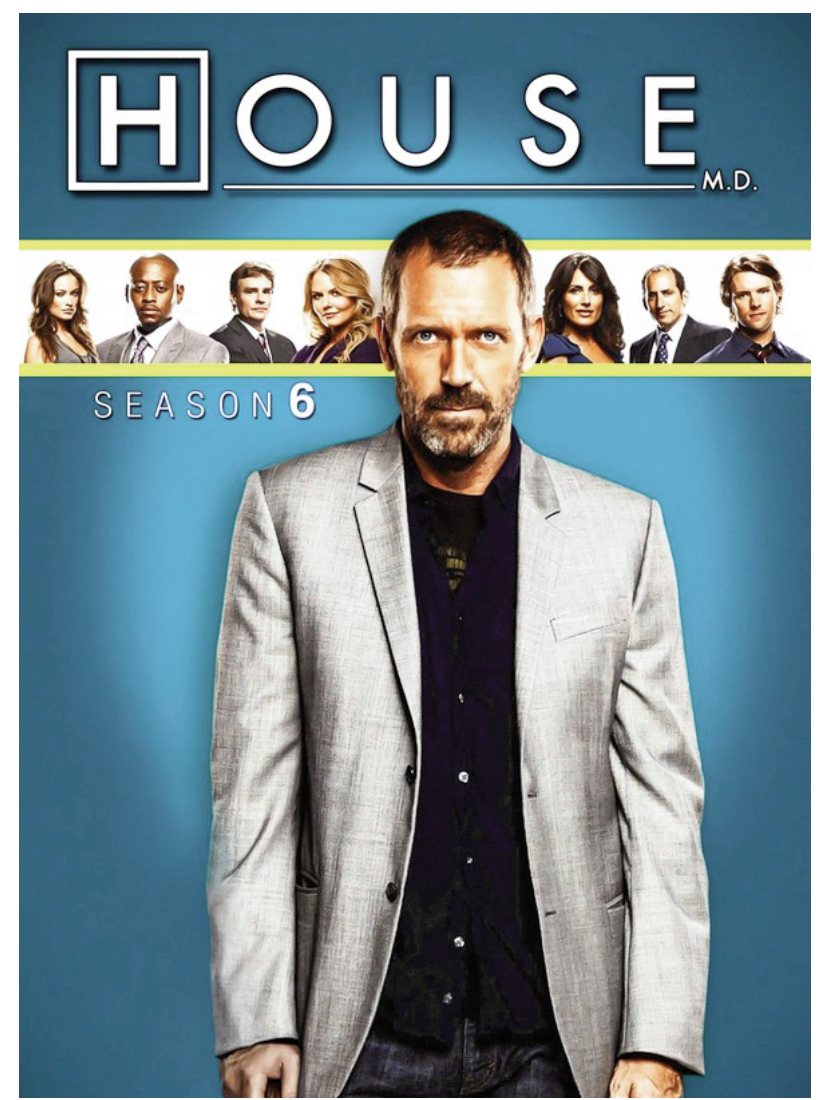

para ser más exactos. Una de las mayores peculiaridades de esta narración es que el protagonista de la serie en general, el doctor Gregory House, adquiere en este relato un papel secundario. Aquí, el personaje más importante es uno de sus ayudantes, el doctor Robert Chase.

Este episodio guarda cierto interés que va más allá de la simple curiosidad médica que ofrece la serie en la mayoría de las ocasiones. Si bien ésta destaca por las retorcidas y misteriosas enfermedades que House debe desenmascarar, como si consistiera en encontrar al responsable de un crimen -no escapa a la vista el claro paralelismo fonético entre el doctor "House" y el investigador policial Sherlock "Holmes", así como sus respectivos ayudantes: "James Wilson" con, el también doctor, "John H. Watson"-. La mentira es uno de los temas que trata la serie de forma general. El doctor House parte en todo momento de la misantrópica premisa de que "todo el mundo miente"2. En la mayoría de las ocasiones, la pieza clave que remedia las extrañas enfermedades de sus pacientes consiste en un detalle que a otros les pasa inadvertidos. House, en su calidad de escéptico y gran observador, se fija en esos detalles que ayudar a desvelar los secretos de las personas que los custodian. Este médico invade la privacidad de sus 
pacientes, los humilla y denigra. A cambio, les salva la vida curando sus enfermedades.

En este episodio se plantean cuestiones morales que afectan directamente al doctor Chase, en particular, y toda la comunidad médica, en general. "La medicina es una actividad que (...) implica que ha de enfrentarse a decisiones complejas y difíciles, muchas veces, trágicas" $^{\prime \prime}$. El doctor Chase, efectivamente, no escapa a esta descripción de su oficio. Por esta razón, el dilema que se plantea en el capítulo tiene relación con dos actitudes activas del médico: encontrar el diagnóstico y curar la enfermedad subyacente, o matar activamente al paciente (por fuera de la regulación de la eutanasia). Matar está por fuera de todo código deontológico y marco legal en general: el homicidio está penado en todos los países. Un médico puede alegar objeción de consciencia y no atender determinados pacientes o procedimientos, como plantea la Doctora Cameron.

Básicamente, la narración estriba en la conveniencia de salvar la vida de un dictador genocida o no hacerlo, traducido en dejarlo morir. Como médico, el juramento hipocrático obliga a Chase a curar a todo aquel que acuda en su ayuda. Esta deontología especifica que el profesional de la medicina se "abstendrá de cuanto lleve consigo perjuicio o afán de dañar"4. En este sentido, la norma establece un principio de acción para cualquier situación. Es, por decirlo así, una regla de carácter general. No obstante, poniendo la lente en lo concreto a través del microscopio, Chase se debate en las consecuencias que traerán consigo dejarse llevar por tal principio. Es decir, mira más allá, se focaliza en los fines. Ello trae consigo una toma de decisiones que pone en jaque la ética de su profesión como la de sus compañeros.

La tarea de este artículo no consiste en establecer juicios valorativos o interpretaciones subjetivas en torno a lo (in)correcto de las acciones de los personajes. El objetivo se basa, primero, en trasladar -de la manera más analítica posible- el choque de ideas que plasma la obra y, segundo, en ahondar en el porqué de los aconteceres de la narración. En otras palabras, el análisis cinematográfico aplicado hará una radiografía de las estructuras narrativas de este episodio y dará a conocer las motivaciones de los personajes que participan en él. Esto servirá para comprender -o no- las decisiones que cada uno toma a lo largo de la narración.

\section{El Tirano}

La estructura de este episodio está configurada por tres grandes tramas independientes. Cada una se desarrolla por separado aunque, a medida que va avanzando la narración, una de ellas se superpone a las demás. La primera consiste en la trama del liderazgo, la riña entre Foreman y House por el mando del equipo de diagnóstico. House ha estado unos meses fuera desintoxicándose de su adicción a la vicodina, por lo que Foreman ha sido elegido por Caddy (la directora del hospital) para capitanear al grupo. House, que trabaja en calidad de asesor hasta que recupere su licencia, queda relegado a un segundo lugar, aunque trata de imponer su voluntad.

En segundo orden, en la trama que denominamos de la "enfermedad secundaria", conocemos que House está viviendo con Wilson, ya que no quiere verse solo ante la tentación de recaer en su adicción. En dicha convivencia, descubre que su compañero tiene un vecino insoportable, veterano de la Guerra de Vietnam, que vive atormentado por el recuerdo de la muerte de un niño al que no pudo rescatar. House alivia su sufrimiento mediante una técnica de medicina psicológica experimental. Queda así solucionada la habitual incógnita, disfrazada de enfermedad, a la que solo House es capaz de dar respuesta.

Por último, la trama de la moral, es la que protagonizan Chase, Cameron y Dibala. Esta es a la que el episodio ofrece un mayor peso narrativo $y$, por ende, en la que este análisis se focalizará. Temáticamente se plantea la conveniencia de aplicar una ética de carácter teleológico (fines) o deontológico (principios) -sin tener en cuenta las posibles consecuencias-. Narrativamente, esta trama versa sobre la capacidad de conmoción y transformación que contienen las dos caras de una misma moneda: la verdad y la mentira. Formalmente, ciertos elementos audiovisuales entrarán en juego para dar mayor significación a aquello que la narración quiere transmitir.

\section{La mentira, el arma letal}

Esta última trama es, paradójicamente, la que da comienzo al episodio y, en su aparente sencillez, se oculta en forma de metáfora narrativa la argucia empleada por Chase al final del capítulo. Todo comienza durante una noche tormentosa, con Dibala en su limusina acompañado de su coronel y el chófer. Se da a conocer un aspecto clave de la vida personal del dictador: su hijo estudia en una prestigiosa universidad estadounidense, pero la prensa nacional ha hecho que odie a su padre por ser quien es.

En un momento dado, dos furgonetas negras aparecen de la nada e inmovilizan el vehículo de Dibala. Ante esta nueva situación de peligro, el coronel baja de la 
limusina empuñando su arma y apunta a un hombre que ha salido de una de ellas con actitud amenazante. Ambos personajes parecen estar al borde de la muerte, bajo la lluvia, mirándose sin pestañear. El coronel ordena en repetidas ocasiones a su contrincante que se tumbe en el suelo. Al final, resulta que tanto el espectador como Dibala y su séquito han sido víctimas de un anticlímax -en el sentido narrativo de no haberse visto cumplidas las expectativas generadas-. El hombre de la furgoneta, simplemente, iba a entregar una citación judicial al dictador, acusándole de genocidio, crímenes contra la humanidad y tortura. Es decir, lo que parecía un claro caso de duelo a muerte, queda resuelto con la simple entrega de una carta. De este modo, una de las formas de la mentira es mostrada en la primera secuencia de la narración. Esta trampa retórica, es decir, aquello que parece ser pero que no es, será la argucia de la que se valdrá Chase al final del episodio para acabar con la vida de Dibala.

Tras varias hipótesis erróneas, el equipo de diagnóstico trata al dictador de esclerodermia. Esta es la última de las hipótesis de House, que impone a todas horas su voluntad amparado en la capacidad persuasiva de su raciocinio. Chase se ofrece voluntario para realizar un análisis de sangre con el que confirmar la propuesta. No obstante, en esa acción estriba el ardid que el médico emplea para matar al dictador. Chase logra engañar a todos, incluida su mujer, trayendo consigo una muestra de sangre falsa con la que hace creer a sus compañeros que, efectivamente, Dibala padece esclerodermia. A pesar de ello, Foreman se muestra reticente. Señala que la muestra de sangre solamente apunta a la supuesta enfermedad, pero no es del todo concluyente. Chase se enfrenta a él pero es necesaria la inocente intervención de Cameron para que su marido se salga con la suya.

Aquí entra en juego la trama personal de este personaje. Cameron convence a Foreman, aludiendo que la inseguridad que los errores que ha cometido con "13" están perjudicando al proceso de diagnóstico de Dibala. Chase demuestra una contención e insensibilidad nunca vistas al observar a su pareja, completamente engañada, abogando por un tratamiento falso que sabe que matará a Dibala, cosa a la que ella se ha opuesto a llevar a cabo solo unos momentos atrás. De este modo, Foreman ordena retirar la medicación para el LDH, la enfermedad que, en su opinión $-y$ contraria a la de House-, estaba matando al dictador.

Tras esto, se expone el clímax de la narración. Da lugar a la escena en la que, finalmente, muere Dibala. El tratamiento para la esclerodermia consiste en la inyección de esteroides en la sangre. Las consecuencias de esto provocan una docena de hemorragias internas en los pulmones del dictador, que muere ahogado en su propia sangre. Metafóricamente, Chase mata a Dibala causándole el mismo síntoma que lo hizo acudir al hospital, cerrando así su ciclo vital.

En la resolución del episodio, Chase confiesa haber cometido el asesinato. Tras ceder a la presión de Foreman, que ha descubierto el "cambiazo" que este llevó a cabo al sustituir una sangre por otra. De este modo, logra confundir el diagnóstico de Dibala por el de un cadáver del depósito que sí debió haber necesitado un tratamiento de esteroides, ya que su cuerpo, el de una mujer de setenta y seis años, sí que tenía tal enfermedad. No obstante, esta anciana sucumbió -por causas naturales- antes de recibir su correspondiente tratamiento. Metafóricamente, este nuevo rostro que adopta la mentira encaja con la argucia narrativa a la que el episodio expone a los espectadores al comienzo, recordemos, el anticlímax.

Aparte del propio Dibala, otro herido por las consecuencias de la artimaña de Chase es Foreman, que se siente doblemente engañado. Por un lado, su amigo le ha mentido, traicionando la amistad que los unía. Por el otro, se ha insultado a su inteligencia ya que, al cambiar la medicación, este se vio despojado de la oportunidad de confirmar su propia hipótesis, el LDH. Continuando con los efectos que Chase ha causado, el doctor plantea un importante dilema a su compañero. Si no dice nada, Foreman pasará a ser cómplice del asesinato y, si lo hace, estará condenando a cadena perpetua a su amigo, además de convertir a Dibala en un mártir en su país, provocando de este modo, la matanza indiscriminada de los Sitibi.

En lo personal, Chase ha sido capaz de mentir a su mujer, Cameron, permitiéndole además participar en su estrategia homicida, aunque de manera inconsciente. Al comienzo de la trama, ella se opone a tratar al dictador. Sin embargo, a medida que avanza la narración, cambia de actitud y opta por una pasividad que le permite dirigirse al dictador como si de un paciente corriente se tratase. Chase, por su lado, parte de una sensación de curiosidad que quiere paliar al inicio del capítulo a una determinación por matar al dictador que lo lleva, como hemos visto, a traicionar la confianza de sus seres más queridos.

\subsection{La mentira, herramienta del mal}

Previamente, antes de matar a Dibala, ciertos acontecimientos dan lugar al odio que Chase acaba sintiendo por el dictador. Todos ellos están profundamente 
marcados por las distintas caras que es capaz de adoptar la mentira. El primero sucede cuando Chase se dirige a pasar consulta. El enfermo al que presta atención es un falso paciente. Resulta ser, en realidad, un activista contrario al régimen de Dibala. Insta a Chase a tomar cartas en el asunto, le suplica no tratarlo ya que eso supondría la muerte de millones de personas en su país. Según cuenta el activista (del que desconocemos el nombre), Dibala mató a su mujer embarazada, incluso le muestra una foto a Chase con la que conmoverle y fomentar la empatía hacia su causa. La máscara del activista es complementada con la mentira de su discurso: su dramático relato resulta ser completamente falso.

La segunda ocasión en la que actúa la mentira ocurre cuando el activista se disfraza de enfermero y se acerca a la habitación de Dibala. Chase descubre sus intenciones al percatarse del infiltrado e, instintivamente, alerta a los guardaespaldas de que detengan a ese hombre. Este aviso es suficiente para que el coronel y los suyos den fin a las intenciones del activista. Una vez inmovilizado, confiesa su mentira. La mujer de la foto no era su esposa, sin embargo, lo que le hicieron sí que era real. Es, por así decirlo, una verdad a medias. En definitiva, otro disfraz con el que vestir la realidad. Según él, las juventudes de Dibala -jóvenes a los que el dictador saca de la calle para armarlos y que luchen en su nombre- mataron y maltrataron el cadáver de aquella mujer. Chase no le da mucha credibilidad a la historia de un hombre que ya lo ha engañado una vez.

La tercera de las acciones en las que la mentira participa activamente, supone para Chase un cambio de percepción radical respecto a su paciente. Ocurre cuando le diagnostican fiebre de Lasa. Al parecer, el mejor remedio para esta enfermedad es un tipo de sangre determinado muy difícil de encontrar. Dibala se las apaña para reclutar a una secuaz Sitibi que, coacciona$\mathrm{da}$, se ofrece a donar su sangre para el dictador. Nadie se atreve a denunciar dicho chantaje y amenaza. Tal y como lo explica Cuddy, prefiere aceptar a esa mujer como donante, que rechazarle y que por ello maten a su familia.

Esta última experiencia parece afectar más a Chase que a los demás. Tras estar en contacto con el activista y ser puesto en situación respecto a lo que ocurre en su país, sumado a la realidad a la que han expuesto a la donante de sangre, generan en él dudas respecto a lo ético que envuelve el caso Dibala. La mentira, en su camaleónica esencia, se convierte en un elemento que desequilibra la inicial estabilidad de doctor Chase.

\section{La verdad, el arco de transformación}

Tal y como se ha expuesto, la mentira es un agente que actúa oculto tras múltiples máscaras. Sin embargo, la verdad tiene un solo rostro y es el de Dibala. Este personaje es capaz de sacar a relucir la naturaleza de cada uno. Por ello, demuestra a Cameron que ella es incapaz de matar, aunque lo intente, pues su ser es puramente bondadoso. No obstante, al sacar a relucir la esencia de Chase, Dibala descubrirá que este médico oculta una frialdad que ni él ni su esposa sospechaban que existía.

En primera instancia, Cameron se opone a tratar al dictador. No puede aceptar el poner sus conocimientos médicos al servicio de un hombre que pretende acabar con la vida de dos millones de personas, la gente perteneciente a la etnia Sitibi, que representa la principal oposición a la dictadura de Dibala. Cuddy le exige, llanamente, que "haga su trabajo". Apelando a la fría y racional burocracia que caracteriza a este personaje. Dibala es huésped del Gobierno de los Estados Unidos y debe ser tratado como tal, reitera. Por otro lado, Chase considera, en un inicio, "interesante" tratar al dictador y defiende que se quede. Más adelante ambos pareceres se sustituirán, siendo Chase quien intente, por todos los medios, expulsar a Dibala del hospital.

En un comienzo, House convence a Foreman de que lo traten con dioxina para descartar cualquier teoría relacionada con el veneno. Así da paso a la primera toma de contacto entre Dibala y Chase, en la que el dictador siembra una semilla de confrontación con el médico. Apunta al acento británico que caracteriza al australiano Chase que, efectivamente, realizó un año de seminario en Gran Bretaña. A esto, el dictador deja patente el rechazo que siente hacia aquellos misioneros que, cuando era niño, acudían a su país preocupados por el alma de sus conciudadanos y no tanto por el hambre que padecían. En cierta manera, Dibala ve reflejado en Chase aquello que odiaba de esos hombres. Él es africano, Chase procede de una ascendencia europea. Él pertenece al tercer mundo, Chase ha sido un hombre acomodado toda su vida. Dibala es militar, Chase es médico, uno se dedica a matar, el otro a sanar. Chase es un hombre de religión, Dibala es un hombre arraigado a la dura realidad de sus orígenes. Por ello, son personas completamente diferentes $\mathrm{y}$, en este caso particular, los polos opuestos no se atraen.

Lo que detona completamente el odio de Chase se muestra cuando el dictador pone la estabilidad emocional de Cameron en juego, en una de las secuencias 
cruciales de la narración. El equipo comienza a tratar a Dibala para la blastomicosis. Ella se dispone a inyectarle el respectivo medicamento cuando el dictador -que ha comenzado a dar síntomas de enajenación- la reta a inyectarle una burbuja de oxígeno con la que provocarle un fallo cardiaco que acabaría con su vida.

A pesar de que previamente había confesado a su marido que no haría nada por salvar la vida del dictador, cuando se presenta la ocasión de encarar la verdad, no tiene las agallas de completar el asesinato. Anteriormente, Dibala ha descubierto que Cameron, de manera encubierta, había sugerido a su (más que fiel) coronel que está perdiendo la cabeza y que sería conveniente acabar con su vida y sustituirle. Cameron se avergüenza de lo que ha intentado hacer y Dibala se lo recrimina: "Puso un arma en su mano (la del Coronel) para que me apuntara en los ojos". Dibala, a modo de mentor, muestra la verdad interior de este personaje: "La he hecho mirarse al espejo. Le he mostrado su verdadero ser", le explica a Chase. A sabiendas de que Cameron no será capaz de llevar a cabo lo que, utilitariamente, sería lo más conveniente para la mayoría Sitibi, Dibala dicta sentencia: "Si me quiere muerto apriete el gatillo, no es tan fácil si tiene que hacerlo uno mismo", le señala.

Esta frase sirve para disipar las dudas de Chase. Comprende que si quiere evitar la muerte de los Sitibi, debe tomar una determinación: actuar o no hacerlo. Las leyendas sobre las Juventudes de Dibala son confirmadas por el propio dictador, cuando Chase le pregunta directamente sobre ello. Según él, "un hombre toma decisiones y hará lo que sea para proteger a su país". De este modo, el doctor aprende la cruda lección de este maestro. Tras esto, Chase lleva a cabo su estratagema y acaba con la vida del dictador. Esta escena es la única vez en la que ambos personajes comparten un momento de intimidad, traducido en una habitación vacía, marcada simbólicamente por la oscuridad y el silencio de la noche. De esta manera se cierra el arco evolutivo de ambos personajes. Tanto Chase como Cameron ven sus respectivas actitudes iniciales intercambiadas tras pasar por el filtro catalizador de Dibala.

\section{Conclusiones. Del principio al fin}

Esta narración plantea el tema moral que discute la conveniencia de salvar la vida a un hombre que admite públicamente que va a cometer un genocidio. Como médico, la tarea del doctor Chase es preservar la vida y evitar el dolor a sus pacientes. Aun así, este personaje se decanta por asesinar al dictador. Existen dos escuelas éticas que dan lugar a justificaciones con las que defender una u otra postura: el deontologismo y el utilitarismo.

Desde una perspectiva kantiana, los principios que rigen el comportamiento humano son aquello a lo que debemos aferrarnos a la hora de tomar decisiones. Por tanto, si el código deontológico de la medicina estipula que un profesional debe sanar a sus pacientes, independientemente de quiénes sean o qué hayan hecho, este debe hacerlo sin importar las consecuencias. Exactamente ahí estriban los motivos que ofrecen una comprensión totalmente opuesta a lo expuesto por la filosofía deontológica.

No son los principios, sino los fines los que importan. Desde esta mirada teleológica, las consecuencias de nuestros actos son lo que deben determinar nuestra conducta y toma de decisiones. Comprendiendo esto, por mucho que Dibala sea un paciente, permitir mantenerlo con vida supondría ser partícipe -indirecto- de la matanza que pretende llevar a cabo cuando esté de vuelta en su país. Chase se decanta por esta última postura moral y decide ejecutar su plan mortal.

El motivo que empuja al doctor se esconde en su interior. Chase se debate interiormente entre dejarse guiar por la razón o por la emoción. Ni una ni otra, sino un término medio entre ambas partes es lo que lo gobierna sus decisiones. Lo que impulsa al doctor a decantarse por la vía del asesinato, consiste en una razón guiada por la emoción, en este caso, la compasión. Ese "padecer con"5 que el activista y la mujer coaccionada despiertan en Chase, le hacen sentir moralmente cuál debe ser su cometido. Y es que los sentimientos, lejos de ser algo que cieguen la mente, sirven para alumbrar el camino que uno debe seguir. Los sentimientos morales ayudan a discernir sobre las cuestiones que nos presenta la vida.

El propio Chase simboliza ese punto medio que representan los sentimientos morales. En un extremo se encuentra el doctor Foreman. Es el más frío, brillante y racional de los tres aprendices de House. Por ello, es el que más se parece a él. Su mayor capacidad intelectual a veces deriva en osadía y prepotencia, cosa que le lleva a cometer errores fatales como herir los sentimientos de sus seres más queridos. Cosa que, a diferencia de House, le hace arrepentirse de ser como es. Foreman no ve diferencias entre tratar a un paciente u otro. Sencillamente, es médico y se dedica a salvar todas las vidas que puede. Por esta lógica, no vive el debate interior que atormenta a Chase.

Al otro extremo está Cameron, que es todo sentimiento. En el pasado se casó con un hombre moribundo 
únicamente por la lástima que sentía hacia él. Tal y como Dibala ha expuesto, ella es incapaz de matar. A pesar de la barbarie que va a cometer el dictador, Cameron no puede arrebatar la vida a otra persona.

Entre estos dos personajes se encuentra Chase. Desde una perspectiva utilitarista, el bien para la mayoría es el bien mayor. Así se excusa ante Foreman, cuando este descubre el crimen acontecido. Chase comprende que si sanaban a Dibala, todas las vidas que el equipo de diagnóstico había salvado hasta la fecha no significarían nada, pues el dictador, él solo, acabaría con cientos de miles personas. Por ello, la narración parece querer decir que lo decidido por Chase era lo más apropiado.

Sin embargo, la obra muestra la otra cara de la moneda. Dibala está muerto, los Sitibi a salvo y Chase camina en libertad. Todo parece en perfecta armonía hasta que llega la última secuencia del episodio. En ella, se muestra el cadáver de Dibala en la morgue del hospital. Junto al cuerpo, un joven de clara ascendencia africana mira el rostro del dictador mientras contiene el llanto. Es el hijo de Dibala, aquél al que el dictador aludía al comienzo del episodio. Una de las víctimas colaterales que Chase ha provocado y que no tenía por qué sentir tal tristeza. La narración guarda, de esta manera, una estructura circular, comienza y acaba con el personaje al que Dibala hace referencia.
Determinar si la decisión tomada por este protagonista es la correcta no es tarea de esta investigación. La narración parece querer defender la postura tomada por el doctor Chase, pues el asesinato que ha cometido no le traen consecuencias penales. No obstante, tal acción lo castiga en el ámbito personal de su vida. Al enterarse de lo sucedido capítulos más adelante, Cameron acaba abandonando a su marido, pues siente que ha cambiado. No lo creía capaz de realizar semejante acción, por mucho que él trate de justificarlo. Puede que Dibala mereciera morir, pero no correspondía a Chase ser el verdugo. Pues, aunque parezca mentira, hasta un dictador como él tenía seres queridos que lo amaban. Por esta razón, el episodio decide cerrar el relato mostrando al hijo de Dibala, la última víctima.

\section{Referencias}

1. Riera J. House vs la realidad [Internet]. El país económico. 12 de agosto de 2016. [citado el 7 de octubre de 2019].

2. Consejo General de Colegios Oficiales de Médicos. Código de deontología médica. Guía de ética médica. Madrid: Consejo General De Colegios Oficiales De Médicos; Julio de 2011. p. 2.

3. Victoria Camps. Presentación. Los fines de la medicina. El establecimiento de unas nuevas prioridades. Cuadernos de la Fundació Víctor Grífols i Lucas. 2005(11):5-7.

4. Wein S. Is House, M.D., always right? Palliat Support Care. 2009;7(1):1-2. 5. Marzabal Albaina I. La compasión en el cine: entre sentimiento y virtud. Rev Med Cine. 2008;4(2):47-57. 